\title{
The Performance Of Mutual Funds In The Period 1945-1964
}

\author{
Michael C. Jensen \\ Harvard Business School \\ MJensen@hbs.edu
}

\begin{abstract}
In this paper I derive a risk-adjusted measure of portfolio performance (now known as "Jensen's Alpha") that estimates how much a manager's forecasting ability contributes to the fund's returns. The measure is based on the theory of the pricing of capital assets by Sharpe (1964), Lintner (1965a) and Treynor (Undated). I apply the measure to estimate the predictive ability of 115 mutual fund managers in the period 1945-1964-that is their ability to earn returns which are higher than those we would expect given the level of risk of each of the portfolios. The foundations of the model and the properties of the performance measure suggested here are discussed in Section II.

The evidence on mutual fund performance indicates not only that these 115 mutual funds were on average not able to predict security prices well enough to outperform a buy-the-marketand-hold policy, but also that there is very little evidence that any individual fund was able to do significantly better than that which we expected from mere random chance. It is also important to note that these conclusions hold even when we measure the fund returns gross of management expenses (that is assume their bookkeeping, research, and other expenses except brokerage commissions were obtained free). Thus on average the funds apparently were not quite successful enough in their trading activities to recoup even their brokerage expenses.
\end{abstract}

Keywords: Jensen's Alpha, mutual fund performance, risk-adjusted returns, forecasting ability, predictive ability.

Journal of Finance, Vol. 23, No. 2 (1967) 389-416.

(C) M. C. Jensen 1967

This document is available on the

Social Science Research Network (SSRN) Electronic Library at: http://papers.ssrn.com/ABSTRACT=244153 


\title{
The Performance Of Mutual Funds In The Period 1945-1964*
}

\author{
Michael C. Jensen \\ Harvard Business School \\ Mjensen@hbs.edu
}

\section{Introduction}

A central problem in finance (and especially portfolio management) has been that of evaluating the "performance" of portfolios of risky investments. The concept of portfolio "performance" has at least two distinct dimensions:

1) The ability of the portfolio manager or security analyst to increase returns on the portfolio through successful prediction of future security prices, and

2) The ability of the portfolio manager to minimize (through "efficient" diversification) the amount of "insurable risk" born by the holders of the portfolio.

The major difficulty encountered in attempting to evaluate the performance of a portfolio in these two dimensions has been the lack of a thorough understanding of the nature and measurement of "risk." Evidence seems to indicate a predominance of risk aversion in the capital markets, and as long as investors correctly perceive the "riskiness" of various assets this implies that "risky" assets must on average yield higher returns than less "risky" assets. ${ }^{1}$ Hence in evaluating the "performance" of portfolios the effects of differential degrees of risk on the returns of those portfolios must be taken into account.

1 Assuming, of course, that investors' expectations are on average correct.

\footnotetext{
* This paper has benefited from comments and criticisms by G. Benston, E. Fama, J. Keilson, H. Weingartner, and especially M. Scholes.
} 
Recent developments in the theory of the pricing of capital assets by Sharpe (1964), Lintner (1965a) and Treynor (Undated) allow us to formulate explicit measures of a portfolio's performance in each of the dimensions outlined above. These measures are derived and discussed in detail in Jensen (1967). However, we shall confine our attention here only to the problem of evaluating a portfolio manager's predictive ability - that is his ability to earn returns through successful prediction of security prices which are higher than those which we could expect given the level of riskiness of his portfolio. The foundations of the model and the properties of the performance measure suggested here (which is somewhat different than that proposed in Jensen (1967)) are discussed in Section II. The model is illustrated in Section III by an application of it to the evaluation of the performance of 115 open end mutual funds in the period 1945-1964.

A number of people in the past have attempted to evaluate the performance of portfolios $^{2}$ (primarily mutual funds), but almost all of these authors have relied heavily on relative measures of performance when what we really need is an absolute measure of performance. That is, they have relied mainly on procedures for ranking portfolios. For example, if there are two portfolios A and B, we not only would like to know whether A is better (in some sense) than B, but also whether A and B are good or bad relative to some absolute standard. The measure of performance suggested below is such an absolute measure. ${ }^{3}$ It is important to emphasize here again that the word "performance" is used here only to refer to a fund manager's forecasting ability. It does not refer to a portfolio's "efficiency" in the Markowitz-Tobin sense. A measure of "efficiency" and its relationship to certain measures of diversification and forecasting ability is derived and discussed in detail in Jensen (1967). For purposes of brevity we confine ourselves here to an examination of a fund manager's forecasting ability which is of interest in and of itself

2 See for example (Cohen and Pogue, 1967; Dietz, 1966; Farrar, 1962; Friend et al., 1962; Friend and Vickers, 1965; Horowitz, 1965; Sharpe, 1966; Treynor, 1965).

3 It is also interesting to note that the measure of performance suggested below is in many respects quite closely related to the measure suggested by Treynor (1965). 
(witness the widespread interest in the theory of random walks and its implications regarding forecasting success).

In addition to the lack of an absolute measure of performance, these past studies of portfolio performance have been plagued with problems associated with the definition of "risk" and the need to adequately control for the varying degrees of riskiness among portfolios. The measure suggested below takes explicit account of the effects of "risk" on the returns of the portfolio. Finally, once we have a measure of portfolio "performance" we also need to estimate the measure's sampling error. That is we want to be able to measure its "significance" in the usual statistical sense. Such a measure of significance also is suggested below.

\section{The Model}

The Foundations of the Model. - As mentioned above, the measure of portfolio performance summarized below is derived from a direct application of the theoretical results of the capital asset pricing models derived independently by Sharpe (1964), Lintner (1965a) and Treynor (Undated). All three models are based on the assumption that (1) all investors are averse to risk, and are single period expected utility of terminal wealth maximizers, (2) all investors have identical decision horizons and homogeneous expectations regarding investment opportunities, (3) all investors are able to choose among portfolios solely on the basis of expected returns and variance of returns, (4) all trans-actions costs and taxes are zero, and (5) all assets are infinitely divisible. Given the additional assumption that the capital market is in equilibrium, all three models yield the following expression for the expected one period return, ${ }^{4} E\left(\tilde{R}_{j}\right)$, on any security (or portfolio) $j$ :

$$
E\left(\tilde{R}_{j}\right)=R_{F}+\square_{j}\left[E\left(\tilde{R}_{M}\right) \square R_{F}\right]
$$

\footnotetext{
4 Defined as the ratio of capital gains plus dividends to the initial price of the security.
} 
where the tildes denote random variables, and

$$
\begin{aligned}
& R_{F} \quad=\text { the one-period risk free interest rate. } \\
& \square_{j} \quad=\frac{\operatorname{cov}\left(\tilde{R}_{j}, \tilde{R}_{M}\right)}{\square^{2} \tilde{R}_{M}} \quad \begin{array}{l}
\text { the measure of risk (hereafter called systematic risk) which } \\
\text { the asset pricing model implies is crucial in determining the } \\
\text { prices of risky assets. }
\end{array} \\
& E\left(\tilde{R}_{M}\right)=\text { the expected one-period return on the "market portfolio" which consists of an }
\end{aligned}
$$

Thus eq. (1) implies that the expected return on any asset is equal to the risk free rate plus a risk premium given by the product of the systematic risk of the asset and the risk premium on the market portfolio. ${ }^{5}$ The risk premium on the market portfolio is the difference between the expected returns on the market portfolio and the risk free rate.

Equation (1) then simply tells us what any security (or portfolio) can be expected to earn given its level of systematic risk, $\square_{j}$. If a portfolio manager or security analyst is able to predict future security prices he will be able to earn higher returns than those implied by eq. (1) and the riskiness of his portfolio. We now wish to show how (1) can be adapted and extended to provide an estimate of the forecasting ability of any portfolio manager. Note that (1) is stated in terms of the expected returns on any security or portfolio $j$ and the expected returns on the market portfolio. Since these expectations are strictly unobservable we wish to show how (1) can be recast in terms of the objectively measurable realizations of returns on any portfolio $j$ and the market portfolio $M$.

In Jensen (1967) it was shown that the single period models of Sharpe, Lintner, and Treynor can be extended to a multiperiod world in which investors are allowed to

$5 \quad$ Note that since $\square^{2}\left(\tilde{R}_{M}\right)$ is constant for all securities the risk of any security is just $\operatorname{cov}\left(\tilde{R}_{j}, \tilde{R}_{M}\right)$. But since $\operatorname{cov}\left(\tilde{R}_{j}, \tilde{R}_{M}\right)=\square^{2}\left(\tilde{R}_{M}\right)$ the risk of the market portfolio is just $\square^{2}\left(\tilde{R}_{M}\right)$, and thus we are really measuring the riskiness of any security relative to the risk of the market portfolio. Hence the systematic risk of the market portfolio, $\operatorname{cov}\left(\tilde{R}_{j}, \tilde{R}_{M}\right) / \square^{2}\left(\tilde{R}_{M}\right)$, is unity, and thus the dimension of the measure of systematic risk has a convenient intuitive interpretation. 
have heterogeneous horizon periods and in which the trading of securities takes place continuously through time. These results indicate that we can generalize eq. (1) and rewrite it as

$$
E\left(\tilde{R}_{j t}\right)=R_{F t}+\square_{j}\left[E\left(\tilde{R}_{M t}\right) \square R_{F t}\right]
$$

where the subscript $t$ denotes an interval of time arbitrary with respect to length and starting (and ending) dates.

It is also shown in Fama (1968) and Jensen (1967) that the measure of risk, $\square_{j}$, is approximately equal to the coefficient $b_{\mathrm{j}}$ in the "market model" given by:

$$
\tilde{R}_{j t}=E\left(\tilde{R}_{j t}\right)+b_{j} \square_{t}+\tilde{e}_{j t} \quad j=1,2, \ldots, N
$$

where $b_{j}$ is a parameter which may vary from security to security and $\square_{t}$ is an unobservable "market factor" which to some extent affects the returns on all securities, and $N$ is the total number of securities in the market. ${ }^{6}$ The variables $\square_{t}$ and the $\tilde{e}_{j t}$ are assumed to be independent normally distributed random variables with

$$
\begin{array}{ll}
E\left(\square_{t}\right)=0 & \\
E\left(\tilde{e}_{j t}\right)=0 & j=1,2, \ldots, N \\
\operatorname{cov}\left(\square_{t}+\tilde{e}_{j t}\right)=0 & j=1,2, \ldots, N
\end{array}
$$

6 The "market model" given in eqs. (2) and (3a)-(3d) is in spirit identical to the "diagonal model" analyzed in considerable detail by Sharpe $(1963 ; 1967)$ and empirically tested by Blume (1968). The somewhat more descriptive term "market model" was suggested by Fama (1968). The "diagonal model" is usually stated as

$$
\tilde{R}_{j t}=a_{j}+b_{j} \tilde{I}_{t}+\tilde{u}_{j t}
$$

where $\tilde{I}$ is some index of market returns, $\tilde{u}_{j}$ is a random variable uncorrelated with $\tilde{I}$, and $a_{j}$ and $b_{j}$ are constants. The differences in specification between (2) and (2a) are necessary in order to avoid the over specification (pointed out by Fama (1968)) which arises if one chooses to interpret the market index I as an average of security returns or as the returns on the market portfolio, M (cf., Lintner (1965a), Sharpe(1964)). That is, if $\tilde{I}$ is some average of security returns then the assumption that $\tilde{u}_{j}$ is uncorrelated with $\tilde{I}$ (equivalent to (3c)) cannot hold since $\tilde{I}$ contains $\tilde{u}_{j}$. 


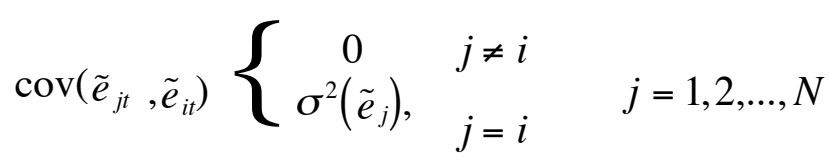

It is also shown in Jensen (1967) that the linear relationships of eqs. (1a) and (2) hold for any length time interval as long as the returns are measured as continuously compounded rates of return. Furthermore to a close approximation the return on the market portfolio can be expressed as ${ }^{7}$

$$
\tilde{R}_{M t} \square E\left(\tilde{R}_{M t}\right)+\square t
$$

Since evidence given in Blume (1968) and Jensen (1967) indicates that the market model, given by eqs. (2) and (3a) $\square(3 \mathrm{~d})$, holds for portfolios as well as individual securities, we can use (2) to recast (la) in terms of ex post returns. ${ }^{8}$ Substituting for $E\left(\tilde{R}_{M t}\right)$ in (la) from (4) and adding $\square_{j} \square_{t}+\tilde{e}_{j t}$ to both sides of (la) we have

7 The return on the market portfolio is given by $\tilde{R}_{M}=\prod_{j=1}^{N} X_{j} \tilde{R}_{j}$ where $X_{j}$ is the ratio of the total value of the $j^{\prime}$ th asset to the total value of all assets. Thus by substitution from (2) we have

$$
\tilde{R}_{M t}=\underset{j}{\square} X_{j} E\left(\tilde{R}_{j t}\right)+\square_{j} X_{j} b_{j} \square_{t}+\square_{j} X_{j} \tilde{e}_{j t}
$$

Note that the first term on the right hand side of (3) is just $E\left(\tilde{R}_{M t}\right)$, and since the market factor $U$ is unique only up to a transformation of scale (cf. (Fama, 1968)) we can scale $U$ such that $\square_{j} X_{j} b_{j}=1$ and the second term becomes just $U$. Furthermore by assumption, the $\tilde{e}_{j t}$ in the third term are independently distributed random variables with $E\left(\tilde{e}_{j t}\right)=0$, and empirical evidence indicates that the $\square^{2}\left(\tilde{e}_{j}\right)$ are roughly of the same order of magnitude as $\square^{2}(\tilde{\square})$ (cf. (Fama, 1968; King, 1966)). Hence the variance of the last term on the right hand side of (3), given by

$$
\left.\square^{2} \prod_{j} X_{j} \tilde{e}_{j}\right]_{0}=\square_{j} X_{j}^{2} \square^{2}\left(\tilde{e}_{j}\right)
$$

will be extremely small since on average $X_{j}$ will be equal to $1 / N_{1}$ and $N$ is very large. But since the expected value of this term 見 $X_{j} e_{j t}$ 具is zero, and since we have shown its variance is extremely small, it is unlikely that it will be very different from zero at any given time. Thus to a very close approximation the returns on the market portfolio will be given by eq. (4).

8 Note that the parameters $\square_{j}$ (in (la)) and $b_{j}$, (in (2)) are not subscripted by $t$ and are thus assumed to be stationary through time. Jensen (1967) has shown (2) to be an empirically valid description of the behavior of the returns on the portfolios of 115 mutual funds, and Blume (1968) has found similar results for the behavior of the returns on individual securities. 


$$
E\left(\tilde{R}_{j t}\right)+\square_{j} \square_{t}+\tilde{e}_{j t} \square R_{F t}+\square_{j}\left[\tilde{R}_{M t} \square \square t \square R_{F t}\right]+\square_{j} \square_{t}+\tilde{e}_{j t}
$$

But from (2) we note that the left hand side of (5) is just $\tilde{R}_{j t}$. Hence (5) reduces to: ${ }^{9}$

$$
\tilde{R}_{j t}=R_{F t}+\square_{j}\left[\tilde{R}_{M t} \square R_{F t}\right]+\tilde{e}_{j t}
$$

Thus assuming that the asset pricing model is empirically valid, ${ }^{10}$ eq. (6) says that the reached returns on any security or portfolio can be expressed as a linear function of its systematic risk, the realized returns on the market portfolio, the risk free rate and a random error, $\tilde{e}_{j t}$, which has an expected value of zero. The term $R_{F t}$ can be subtracted from both sides of eq. (6), and since its coefficient is unity the result is

$$
\tilde{R}_{j t} \square R_{F t}=\square_{j}\left[\tilde{R}_{M t} \square R_{F t}\right]+\tilde{e}_{j t}
$$

The left hand side of (7) is the risk premium earned on the $j$ 'th portfolio. As long as the asset pricing model is valid this premium is equal to $\square_{j}\left[\tilde{R}_{M t} \square R_{F t}\right]$ plus the random error term $\tilde{e}_{j t}$.

The Measure of Performance.-Furthermore eq. (7) may be used directly for empirical estimation. If we wish to estimate the systematic risk of any individual security or of an unmanaged portfolio the constrained regression estimate of $\square_{j}$ in eq. (7) will be an efficient estimate ${ }^{11}$ of this systematic risk. However, we must be very careful when applying the equation to managed portfolios. If the manager is a superior forecaster (perhaps because of special knowledge not available to others) he will tend to systematically select securities which realize $\tilde{e}_{j t}>0$. Hence his portfolio will earn more

In addition it will be shown below that any non-stationary which might arise from attempts to increase returns by changing the riskiness of the portfolio according to forecasts about the market factor $U$ lead to relatively few problems.

9 Since the error of approximation in (6) is very slight (cf. (Jensen, 1967), and note 7), we henceforth use the equality.

10 Evidence given in Jensen (1967) suggests this is true.

11 In the statistical sense of the term. 
than the "normal" risk premium for its level of risk. We must allow for this possibility in estimating the systematic risk of a managed portfolio.

Allowance for such forecasting ability can be made by simply not constraining the estimating regression to pass through the origin. That is, we allow for the possible existence of a non-zero constant in eq. (7) by using (8) as the estimating equation.

$$
\tilde{R}_{j t} \square R_{F t}=\square_{j}+\square_{j}\left[\tilde{R}_{M t} \square R_{F t}\right]+\tilde{u}_{j t}
$$

The new error term $\tilde{u}_{j t}$ will now have $E\left(\tilde{u}_{j t}\right)=0$, and should be serially independent. ${ }^{12}$

Thus if the portfolio manager has an ability to forecast security prices, the intercept, $\square_{j}$, in eq. (8) will be positive. Indeed, it represents the average incremental rate of return on the portfolio per unit time which is due solely to the manager's ability to forecast future security prices. It is interesting to note that a naive random selection buy and hold policy can be expected to yield a zero intercept. In addition if the manager is not doing as well as a random selection buy and hold policy, $\square_{j}$ will be negative. At first glance it might seem difficult to do worse than a random selection policy, but such results may very well be due to the generation of too many expenses in unsuccessful forecasting attempts.

However, given that we observe a positive intercept in any sample of returns on a portfolio we have the difficulty of judging whether or not this observation was due to mere random chance or to the superior forecasting ability of the portfolio manager. Thus in order to make inferences regarding the fund manager's forecasting ability we need a measure of the standard error of estimate of the performance measure. Least squares regression theory provides an estimate of the dispersion of the sampling distribution of the intercept $\square_{j}$. Furthermore, the sampling distribution of the estimate, $\square_{j}$, is a student $t$ distribution with $n_{j} \square 2$ degrees of freedom. These facts give us the information needed to

12 If $\tilde{u}_{j t}$ were not serially independent the manager could increase his return even more by taking account of the information contained in the serial dependence and would therefore eliminate it. 
make inferences regarding the statistical significance of the estimated performance measure.

It should be emphasized that in estimating $\square_{j}$, the measure of performance, we are explicitly allowing for the effects of risk on return as implied by the asset pricing model. Moreover, it should also be noted that if the model is valid, the particular nature of general economic conditions or the particular market conditions (the behavior of $U$ ) over the sample or evaluation period has no effect whatsoever on the measure of performance. Thus our measure of performance can be legitimately compared across funds of different risk levels and across differing time periods irrespective of general economic and market conditions.

The Effects of Non-Stationarity of the Risk Parameter. - It was pointed out earlier ${ }^{13}$ that by omitting the time subscript from $\square_{j}$ (the risk parameter in eq. (8)) we were implicitly assuming the risk level of the portfolio under consideration is stationary through time. However, we know this need not be strictly true since the portfolio manager can certainly change the risk level of his portfolio very easily. He can simply switch from more risky to less risky equities (or vice versa), or he can simply change the distribution of the assets of the portfolio between equities, bonds and cash. Indeed the portfolio manager may consciously switch his portfolio holdings between equities, bonds and cash in trying to outguess the movements of the market.

This consideration brings us to an important issue regarding the meaning of "forecasting ability." A manager's forecasting ability may consist of an ability to forecast the price movements of individual securities and/or an ability to forecast the general behavior of security prices in the future (the "market factor" $U$ in our model). Therefore we want an evaluation model which will incorporate and reflect the ability of the

13 See note 8 above. 
manager to forecast the market's behavior as well as his ability to choose individual issues.

Fortunately the model outlined above will also measure the success of these market forecasting or "timing" activities as long as we can assume that the portfolio manager attempts on average to maintain a given level of risk in his portfolio. More formally as long as we can express the risk of the $j$ 'th portfolio at any time $t$ as

$$
\tilde{\square}_{j}=\square_{j}+\square_{j t}
$$

where $\square_{j}$ is the "target" risk level which the portfolio manager wishes to maintain on average through time, and $\square_{j t}$ is a normally distributed random variable (at least partially under the manager's control) with $E\left(\square_{j t}\right)=0$. The variable $\square_{j t}$ is the vehicle through which the manager may attempt to capitalize on any expectations he may have regarding the behavior of the market factor $\tilde{\square}$ in the next period. For example if the manager (correctly) perceives that there is a higher probability that $U$ will be positive (rather than negative) next period, he will be able to increase the returns on his portfolio by increasing its risk, ${ }^{14}$ i.e., by making $\square_{j t}$ positive this period. On the other hand he can reduce the losses (and therefore increase the average returns) on the portfolio by reducing the risk level of the portfolio (i.e., making $\square_{i t}$ negative) when the market factor $U$ is expected to be negative. Thus if the manager is able to forecast market movements to some extent, we should find a positive relationship between $\square_{j t}$ and $\square_{t}$. We can state this relationship formally as:

$$
\square_{j t}=a_{j} \square_{t}+\tilde{w}_{j t}
$$

where the error term $\tilde{w}_{j t}$ is assumed to be normally distributed with $E\left(\tilde{w}_{j t}\right)=0$. The coefficient $a_{j}$ will be positive if the manager has any forecasting ability and zero if he

\footnotetext{
14 Perhaps by shifting resources out of bonds and into equities, or if no bonds are currently held, by shifting into higher risk equities or by borrowing funds and investing them in equities.
} 
has no forecasting ability. We can rule out $a_{j}<0$, since as a conscious policy this would be irrational. Moreover, we can rule out $a_{j}<0$ caused by perverse forecasting ability since this also implies knowledge of $\square_{t}$ and would therefore be reflected in a positive $a_{j}$ as long as the manager learned from past experience. Note also that eq. (10) includes no constant term since by construction this would be included in $\square_{j}$ in eq. (9). In addition we note that while $a_{j}$ will be positive only if the manager can forecast $\square$, its size will depend on the manager's willingness to bet on his forecasts. His willingness to bet on his forecasts will of course depend on his attitudes towards taking these kinds of risks and the certainty with which he views his estimates.

Substituting from (9) into (8) the more general model appears as

$$
\tilde{R}_{j t} \square R_{F t}=a_{j}+\left(\square_{j}+\square_{j t}\right)\left[\tilde{R}_{M t} \square R_{F t}\right]+\tilde{u}_{j t}
$$

Now as long as the estimated risk parameter $\hat{\square}$ is an unbiased estimate of the average risk level $\square_{j}$, the estimated performance measure $\left(\square_{j}\right)$ will also be unbiased. Under the assumption that the forecast error $\tilde{w}_{j t}$ is uncorrelated with $\square_{t}$ (which is certainly reasonable), it can be shown ${ }^{15}$ that the expected value of the least squares estimator $\hat{\square}_{j}$ is:

$$
E\left(\hat{\square}_{j}\right)=\frac{\operatorname{cov}\left[\left(\tilde{R}_{j t} \square R_{F t}\right),\left(\tilde{R}_{M t} \square R_{F t}\right)\right]}{\square^{2}\left(\tilde{R}_{M}\right)}=\square_{j} \square a_{j} E\left(R_{M}\right)
$$

Thus the estimate of the risk parameter is biased downward by an amount given by $a_{j} E\left(\tilde{R}_{M}\right)$, where $a_{j}$ is the parameter given in eq. (10) (which describes the relationship between $\square_{j t}$ and $\square_{t}$. By the arguments given earlier $a_{j}$ can never be negative and will be equal to zero when the manager possesses no market forecasting ability. This is important since it means that if the manager is unable to forecast general market movements we

\footnotetext{
15 By substitution from (11) into the definition of the covariance and by the use of eq. (10), the assumptions of the market model given in (3a)-(3d), and the fact that $\square^{2}\left(\tilde{R}_{M}\right) \square \square^{2}(\square)$ (see note 7).
} 
obtain an unbiased estimate of his ability to increase returns on the portfolio by choosing individual securities which are "undervalued."

However, if the manager does have an ability to forecast market movements we have seen that $a_{j}$ will be positive and therefore as shown in eq. (12) the estimated risk parameter will be biased downward. This means, of course, that the estimated performance measure $(\square)$ will be biased upward (since the regression line must pass through the point of sample means).

Hence it seems clear that if the manager can forecast market movements at all we most certainly should see evidence of it since our techniques will tend to overstate the magnitude of the effects of this ability. That is, the performance measure, $\square_{j}$, will be positive for two reasons: (1) the extra returns actually earned on the portfolio due to the manager's ability, and (2) the positive bias in the estimate of $\square_{j}$ resulting from the negative bias in our estimate of $\square_{j}$.

\section{The Data And Empirical Results}

The Data.-The sample consists of the returns on the portfolios of 115 open end mutual funds for which net asset and dividend information was available in Wiesenberger's Investment Companies for the ten-year period 1955-64. ${ }^{16}$ The funds are listed in Table 1 along with an identification number and code denoting the fund objectives (growth, income, etc.). Annual data were gathered for the period 1955-64 for all 115 funds and as many additional observations as possible were collected for these funds in the period $1945-54$

16 The data were obtained primarily from the 1955 and 1965 editions of Wiesenberger (1955 and 1965), but some data not available in these editions were taken from the 1949-54 editions. Data on the College Retirement Equities Fund (not listed in Wiesenberger) were obtained directly from annual reports. All per share data were adjusted for stock splits and stock dividends to represent an equivalent share as of the end of December1964. 
TABLE 1

Listing Of 115 Open End Mutual Funds In The Sample

\begin{tabular}{|c|c|c|}
\hline $\begin{array}{c}\text { ID } \\
\text { Number }\end{array}$ & Code $^{1}$ & Fund \\
\hline 140 & 0 & Aberdeen Fund \\
\hline 141 & 0 & Affiliated Fund, Inc. \\
\hline 142 & 2 & American Business Shares, Inc. \\
\hline 144 & 3 & American Mutual Fund, Inc. \\
\hline 145 & 4 & Associated Fund Trust \\
\hline 146 & 0 & Atomics, Physics + Science Fund, Inc. \\
\hline 147 & 2 & Axe-Houghton Fund B, Inc. \\
\hline 1148 & 2 & Axe-Houghton Fund A, Inc. \\
\hline 2148 & 0 & Axe-Houghton Stock Fund, Inc. \\
\hline 150 & 3 & Blue Ridge Mutual Fund, Inc. \\
\hline 151 & 2 & Boston Fund, Inc. \\
\hline 152 & 4 & Broad Street Investing Corp. \\
\hline 153 & 3 & Bullock Fund, Ltd. \\
\hline 155 & 0 & Canadian Fund, Inc. \\
\hline 157 & 0 & Century Shares Trust \\
\hline 158 & 0 & The Channing Growth Fund \\
\hline 1159 & 0 & Channing Income Fund, Inc. \\
\hline 2159 & 3 & Channing Balanced Fund \\
\hline 160 & 3 & Channing Common Stock Fund \\
\hline 162 & 0 & Chemical Fund, Inc. \\
\hline 163 & 4 & The Colonial Fund, Inc. \\
\hline 164 & 0 & Colonial Growth + Energy Shares, Inc. \\
\hline 165 & 2 & Commonwealth Fund-Plan C \\
\hline 166 & 2 & Commonwealth Investment Co. \\
\hline 167 & 3 & Commonwealth Stock Fund \\
\hline 168 & 2 & Composite Fund, Inc. \\
\hline 169 & 4 & Corporate Leaders Trust Fund Certificates, Series "B" \\
\hline 171 & 3 & Delaware Fund, Inc. \\
\hline 172 & 0 & De Vegh Mutual Fund, Inc. (No Load) \\
\hline 173 & 0 & Diversified Growth Stock Fund, Inc. \\
\hline 174 & 2 & Diversified Investment Fund, Inc. \\
\hline 175 & 4 & Dividend Shares, Inc. \\
\hline 176 & 0 & Dreyfus Fund Inc. \\
\hline 177 & 2 & Eaton + Howard Balanced Fund \\
\hline 178 & 3 & Eaton + Howard Stock Fund \\
\hline 180 & 3 & Equity Fund, Inc. \\
\hline 182 & 3 & Fidelity Fund, Inc. \\
\hline 184 & 3 & Financial Industrial Fund, Inc. \\
\hline 185 & 3 & Founders Mutual Fund \\
\hline 1186 & 0 & Franklin Custodian Funds, Inc.-Utilities Series \\
\hline 2186 & 0 & Franklin Custodial Funds, Inc.-Common Stock Series \\
\hline 187 & 3 & Fundamental Investors, Inc. \\
\hline 188 & 2 & General Investors Trust \\
\hline 189 & 0 & Growth Industry Shares, Inc. \\
\hline 190 & 4 & Group Securities-Common Stock Fund \\
\hline 1191 & 0 & Group Securities-Aerospace-Science Fund \\
\hline 2191 & 2 & Group Securities-Fully Administered Fund \\
\hline 192 & 3 & Guardian Mutual Fund, Inc. (No Load) \\
\hline 193 & 3 & Hamilton Funds, Inc. \\
\hline 194 & 0 & Imperial Capital Fund, Inc. \\
\hline 195 & 2 & Income Foundation Fund, Inc. \\
\hline
\end{tabular}


TABLE 1 (Continued)

\begin{tabular}{|c|c|c|}
\hline $\begin{array}{c}\text { ID } \\
\text { Number }\end{array}$ & Code $^{1}$ & Fund \\
\hline 197 & 1 & Incorporated Income Fund \\
\hline 198 & 3 & Incorporated Investors \\
\hline 200 & 3 & The Investment Company of America \\
\hline 201 & 2 & The Investors Mutual, Inc. \\
\hline 202 & 3 & Investors Stock Fund, Inc. \\
\hline 203 & 1 & Investors Selective Fund, Inc. \\
\hline 205 & 3 & Investment Trust of Boston \\
\hline 206 & 2 & Istel Fund, Inc. \\
\hline 207 & 3 & The Johnston Mutual Fund Inc. (No-Load) \\
\hline 208 & 3 & Keystone High-Grade Common Stock Fund (S-1) \\
\hline 1209 & 4 & Keystone Income Common Stock Fund (S-2) \\
\hline 2209 & 0 & Keystone Growth Common Satock Fund (S-3) \\
\hline 210 & 0 & Keystone Lower-Priced Common Stock Fund (S-4) \\
\hline 1211 & 1 & Keystone Income Fund-(K-1) \\
\hline 2211 & 0 & Keystone Growth Fund (K-2) \\
\hline 1212 & 1 & The Keystone Bond Fund (B-3) \\
\hline 2212 & 1 & The Keystone Bond Fund (B-4) \\
\hline 215 & 2 & Loomis-Sayles Mutual Fund, Inc. (No Load) \\
\hline 216 & 0 & Massachusetts Investors Growth Stock Fund, Inc. \\
\hline 217 & 3 & Massachusetts Investors Trust \\
\hline 218 & 2 & Massachusetts Life Fund \\
\hline 219 & 4 & Mutual Investing Foundation, MIF Fund \\
\hline 220 & 2 & Mutual Investment Fund, Inc. \\
\hline 221 & 0 & National Investors Corporation \\
\hline 222 & 4 & National Securities Stock Series \\
\hline 1223 & 0 & National Securities-Growth Stock Series \\
\hline 2223 & 1 & National Securities-Income Series \\
\hline 224 & 1 & National Securities-Dividend Series \\
\hline 225 & 2 & Nation-Wide Securities Company, Inc. \\
\hline 226 & 2 & New England Fund \\
\hline 227 & 4 & Northeast Investors Trust (No Load) \\
\hline 231 & 3 & Philadelphia Fund, Inc. \\
\hline 232 & 4 & Pine Street Fund, Inc. (No Load) \\
\hline 233 & 3 & Pioneer Fund, Inc. \\
\hline 234 & 0 & T. Rowe Price Growth Stock Fund, Inc. (No Load) \\
\hline 235 & 1 & Puritan Fund, Inc. \\
\hline 236 & 2 & The George Putnam Fund of Boston \\
\hline 239 & 2 & Research Investing Corp. \\
\hline 240 & 2 & Scudder, Stevens + Clark Balanced Fund, Inc. (No Load) \\
\hline 241 & 3 & Scudder, Stevens + Clark Common Stock Fund, Inc. (No Load) \\
\hline 243 & 3 & Selected American Shares, Inc. \\
\hline 244 & 2 & Shareholders' Trust of Boston \\
\hline 245 & 3 & State Street Investment Corporation (No Load) \\
\hline 246 & 2 & Stein Roe + Farnham Balanced Fund, Inc. (No Load) \\
\hline 247 & 0 & Stein Roe + Farnham International Fund, Inc. (No Load) \\
\hline 249 & 0 & Television-Electronics Fund, Inc. \\
\hline 250 & 0 & Texas Fund, Inc. \\
\hline 251 & 3 & United Accumulative Fund \\
\hline 252 & 4 & United Income Fund \\
\hline 253 & 0 & United Science Fund \\
\hline 254 & 1 & The Value Line Income Fund, Inc. \\
\hline 255 & 0 & The Value Line Fund, Inc. \\
\hline
\end{tabular}


TABLE 1 (Continued)

\begin{tabular}{ccl}
\hline \hline $\begin{array}{c}\text { ID } \\
\text { Number }\end{array}$ & Code $^{1}$ & \\
\hline 256 & 4 & Washington Mutual Investors Fund, Inc. \\
257 & 2 & Wellington Fund, Inc. \\
259 & 3 & Wisconsin Fund, Inc. \\
260 & 2 & Composite Bond and Stock Fund, Inc. \\
1261 & 3 & Crown Western-Diversified Fund (D-2) \\
2261 & 2 & Dodge + Cox Balanced Fund (No Load) \\
2262 & 2 & Fiduciary Mutual Investing Company, Inc. \\
263 & 4 & The Knickerbocker Fund \\
267 & 4 & Southwestern Investors, Inc. \\
1268 & 2 & Wall Street Investing Corporation \\
2268 & 2 & Whitehall Fund, Inc. \\
1000 & 0 & College Retirement Equities Fund \\
\hline Wiesenberger classification as to fund investment objectives: $0=$ Growth, $1=$ Income, $2=$ Balanced, \\
$3=$ Growth-Income, 4= Income-Growth.
\end{tabular}

For this earlier period, 10 years of complete data were obtained for 56 of the original 115 funds.

Definitions of the Variables. - The following are the exact definitions of the variables used in the estimation procedures:

$\tilde{S}_{t}=$ Level of the Standard and Poor Composite 500 price index $^{17}$ at the end of year $t$.

$\tilde{D}_{t}=$ Estimate of dividends received on the market portfolio in year $t$ as measured by annual observations on the four quarter moving average ${ }^{18}$ of the dividends paid by the companies in the composite 500 Index (stated on the same scale as the level of the S\&P 500 Index).

$\tilde{R}_{M t}=\log _{e}=\frac{-\tilde{S}_{t}+\tilde{D}_{t}}{S_{t \square 1}}-\frac{\text { The estimated annual continuously compounded rate of return on }}{\text { the market portfolio } M \text { for year } t \text {. }}$

$\tilde{N} A_{j t} \quad=$ Per share net asset value of the $\mathrm{j}^{\prime}$ th fund at the end of year $t$.

$I \tilde{D}_{j t} \quad=$ Per share "income" dividends paid by the $\mathrm{j}$ 'th fund during year $t$.

$\tilde{C} G_{j t}=$ Per share "Capital gains" distributions paid by the j'th fund during year $t$.

$\tilde{R}_{j t}=\log _{e}$ 目 $\frac{\tilde{N} A_{j t}+I \tilde{D}_{j t}+\tilde{C} G_{j t} \text { 目 }}{N A_{j, t \square 1}}=\begin{aligned} & \text { The annual continuously compounded rate of } \\ & \text { return on the j'th fund during year } t \text {. (Adjusted } \\ & \text { for splits and stock dividends.) }\end{aligned}$

17 Obtained from Standard and Poor (1964). Prior to March 1, 1957, the S \& P index was based on only 90 securities (50 industrials, 20 rails and 20 utilities) and hence for the earlier period the index is a poorer estimate of the returns on the market portfolio.

18 Obtained from Standard and Poor (1964). Since the use of this moving average introduces measurement errors in the index returns it would be preferable to use an index of the actual dividends, but such an index is not available.

19 Note that while most funds pay dividends on a quarterly basis we treat all dividends as though they were paid as of December 31 only. This assumption of course will cause the measured returns on the fund 
$r_{t}=$ Yield to maturity of a one-year government bond at the beginning of year $t$ (obtained from Treasury Bulletin yield curves).

$R_{F t}=\log _{e}\left(1+r_{t}\right) \quad=$ Annual continuously compounded risk free rate of return for year $t$.

$n_{j} \quad=$ The number of yearly observations of the $\mathrm{j}$ 'th fund. $10 \square n_{j} \square 20$.

The Empirical Results.-Table 2 presents some summary statistics of the frequency distributions of the regression estimates of the parameters of eq. (8) for all 115 mutual funds using all sample data available for each fund in the period 1945-64. The table presents the mean, median, extreme values, and mean absolute deviation of the 115 estimates of $U, \square, r^{2}$, and $\square\left(u_{t}, u_{\square \square}\right)$ (the first order autocorrelation of residuals). As can be seen in the table the average intercept was -.011 with a minimum value of -.078 and a maximum value of .058 . We defer a detailed discussion of the implications of these estimated intercepts for a moment.

TABLE 2

Summary Of Estimated Regression Statistics For Equation (8) For 115 Mutual Funds Using All Sample Data Available In The Period 1945-64. Returns Calculated Net Of All Expenses $\tilde{R}_{j t} \square R_{F t}=\square_{j}+\square_{j}\left[\tilde{R}_{M t} \square R_{F t}\right]+\tilde{u}_{j t} \quad \mathrm{j}=1,2, \ldots, 115$

\begin{tabular}{|c|c|c|c|c|c|}
\hline \multirow[b]{2}{*}{ Item } & \multirow{2}{*}{$\begin{array}{l}\text { Mean } \\
\text { Value }\end{array}$} & \multirow{2}{*}{$\begin{array}{c}\text { Median } \\
\text { Value }\end{array}$} & \multicolumn{2}{|c|}{ Extreme Values } & \multirow{2}{*}{$\begin{array}{c}\text { Mean } \\
\text { Absolute } \\
\text { Deviation }\end{array}$} \\
\hline & & & Minimum & Maximum & \\
\hline$\overline{\square_{j}}$ & -.011 & -.009 & -0.080 & 0.058 & .016 \\
\hline$\hat{\square}$ & .840 & .848 & 0.219 & 1.405 & .162 \\
\hline$\hat{r}^{2}$ & .865 & .901 & 0.445 & 0.977 & .074 \\
\hline$\tilde{U}\left(\tilde{u}_{t}, \tilde{u}_{\square !}\right) * *$ & -.077 & -.064 & -0.688 & 0.575 & .211 \\
\hline$n$ & 17.0 & 19.0 & 10.0 & 20.0 & 3.12 \\
\hline
\end{tabular}

* Defined as $\frac{\prod_{i \prod 1}\left|\bar{x} \square x_{1}\right|}{115}$

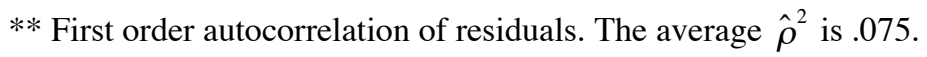

Since the average value of $\square$ was only .840 , on average these funds tended to hold portfolios which were less risky than the market portfolio. Thus any attempt to compare the average returns on these funds to the returns on a market index without explicit adjustment for differential riskiness would be biased against the funds. The average received, but the data needed to accomplish this are not easily available. However, the resulting bias should be quite small. In addition, the same bias is incorporated into the measured returns on the market portfolio. 
squared correlation coefficient, $\hat{r}^{2}$, was .865 and indicates in general that eq. (8) fits the data for most of the funds quite closely. The average first order autocorrelation of residuals, -.077 , is quite small as expected.

Our primary concern in this paper is the interpretation of the estimated intercepts. They are presented in Table 3 along with the fund identification number and the " $\mathrm{t}$ " values and sample sizes. The observations are ordered from lowest to highest on the basis of $\vec{D}$. The estimates range from -.0805 to +.0582 . Table 4 and Figures $1-4$ present summary frequency distributions of these estimates (along with the distributions of the coefficients estimated for several other time intervals which will be discussed below).

In order to obtain additional information about the forecasting success of fund managers eq. (8) was also estimated using fund returns calculated before deduction of fund expenses as well as after. Fund loading charges were ignored in all cases. ${ }^{20}$ Columns 1 and 2 of Table 4 and Figures 1 and 2 present the frequency distributions of the estimated $\hat{\square}$ 's obtained by using all sample data available for each fund. The number of observations in the estimating equation varies from 10 to 20 and the time periods are obviously not all identical. Column 1 and Figure 1 present the frequency distribution of the 115 intercepts estimated on the basis of fund returns calculated net of all expenses. Column 2 of Table 4 and Figure 2 present the frequency distributions of the estimates obtained from the fund returns calculated before deductions of management expenses (as given by Wiesenberger (1955 and 1965) $\left.)^{21}\right)$

20 The loading charges have been ignored since our main interest here is not to evaluate the funds from the standpoint of the individual investor but only to evaluate the fund managers' forecasting ability

21 Actual expense data were available only for the 10 years 1955-64. Therefore in estimating gross returns for the years 1945-54 the expense ratio for 1955 was added (before adjustment to a continuous base) to the returns for these earlier years. 


\section{TABLE 3}

Estimated Intercepts, $\dot{\square}$, And “ $t$ " Values For Individual Mutual Funds Calculated From Equation 8 And All Sample Data Available In The Period 1945-64 Using Net Returns

\begin{tabular}{|c|c|c|c|}
\hline $\begin{array}{l}\text { Fund ID } \\
\text { Number }\end{array}$ & $\dot{D}$ & $t(\hat{\square})=\frac{\square}{\square(\hat{\square})}$ & $\begin{array}{l}\text { Number of } \\
\text { Observations }\end{array}$ \\
\hline 1191 & -.0805 & -1.61 & 13 \\
\hline 2211 & -.0783 & -1.91 & 14 \\
\hline 198 & -.0615 & -4.82 & 20 \\
\hline 222 & -.0520 & -4.43 & 20 \\
\hline 160 & -.0493 & -2.41 & 17 \\
\hline 146 & -.0425 & -1.80 & 11 \\
\hline 1261 & -.0424 & -2.47 & 18 \\
\hline 2148 & -.0417 & -1.89 & 20 \\
\hline 184 & -.0416 & -4.44 & 20 \\
\hline 2209 & -.0412 & -2.07 & 14 \\
\hline 224 & -.0411 & -1.72 & 13 \\
\hline 158 & -.0410 & -2.08 & 13 \\
\hline 164 & -.0376 & -1.58 & 13 \\
\hline 254 & -.0372 & -2.17 & 12 \\
\hline 2223 & -.0370 & -3.27 & 20 \\
\hline 194 & -.0346 & -1.27 & 13 \\
\hline 171 & -.0337 & -2.57 & 20 \\
\hline 220 & -.0332 & -2.74 & 20 \\
\hline 155 & -.0324 & -1.61 & 12 \\
\hline 263 & -.0320 & -1.88 & 20 \\
\hline 255 & -.0305 & -1.10 & 14 \\
\hline 210 & -.0299 & -1.00 & 13 \\
\hline 247 & -.0294 & -1.35 & 10 \\
\hline 1223 & -.0281 & -1.27 & 18 \\
\hline 205 & -.0278 & -0.60 & 20 \\
\hline 167 & -.0256 & -1.60 & 11 \\
\hline 253 & -.0249 & -1.25 & 14 \\
\hline 189 & -.0229 & -1.27 & 18 \\
\hline 145 & -.0224 & -2.16 & 20 \\
\hline 231 & -.0220 & -1.53 & 14 \\
\hline 190 & -.0213 & -1.53 & 20 \\
\hline 193 & -.0210 & -1.53 & 16 \\
\hline 147 & -.0207 & -2.51 & 20 \\
\hline 173 & -.0191 & -0.54 & 12 \\
\hline 243 & -.0190 & -1.82 & 20 \\
\hline 187 & -.0189 & -2.04 & 20 \\
\hline 174 & -.0188 & -1.75 & 20 \\
\hline 2191 & -.0176 & -1.49 & 20 \\
\hline 197 & -.0157 & -0.80 & 10 \\
\hline 249 & -.0155 & -0.74 & 16 \\
\hline 140 & -.0155 & -1.22 & 20 \\
\hline 1148 & -.0143 & -1.02 & 20 \\
\hline 182 & -.0136 & -1.26 & 20 \\
\hline 1211 & -.0134 & -0.80 & 14 \\
\hline 251 & -.0122 & -0.95 & 20 \\
\hline 1159 & -.0120 & -0.67 & 11 \\
\hline 241 & -.0117 & -1.04 & 20 \\
\hline 216 & -.0116 & -0.76 & 20. \\
\hline
\end{tabular}


TABLE 3 (Continued)

\begin{tabular}{|c|c|c|c|}
\hline $\begin{array}{l}\text { Fund ID } \\
\text { Number }\end{array}$ & $\dot{D}$ & $t(\hat{\square})=\frac{\square}{\square(\hat{\square})}$ & $\begin{array}{l}\text { Number of } \\
\text { Observations }\end{array}$ \\
\hline 219 & -.0115 & -1.12 & 20 \\
\hline 195 & -.0111 & -1.23 & 20 \\
\hline 180 & -.0111 & -1.15 & 20 \\
\hline 202 & -.0111 & -0.86 & 19 \\
\hline 1209 & -.0108 & -0.79 & 14 \\
\hline 153 & -.0103 & -0.99 & 20 \\
\hline 150 & -.0099 & -1.14 & 13 \\
\hline 2159 & -.0094 & -0.85 & 13 \\
\hline 252 & -.0093 & -0.85 & 20 \\
\hline 188 & -.0089 & -0.84 & 20 \\
\hline 200 & -.0088 & -0.75 & 20 \\
\hline 239 & -.0087 & -0.23 & 10 \\
\hline 165 & $\sim 0082$ & -0.52 & 10 \\
\hline 235 & -.0081 & -0.55 & 17 \\
\hline 259 & -.0080 & -0.53 & 20 \\
\hline 2212 & -.0080 & -0.44 & 14 \\
\hline 244 & -.0080 & -0.73 & 16 \\
\hline 166 & -.0080 & -0.97 & 20 \\
\hline 163 & -.0076 & -0.39 & 20 \\
\hline 240 & -.0073 & -0.82 & 20 \\
\hline 2261 & -.0061 & -0.66 & 20 \\
\hline 185 & -.0061 & -0.69 & 20 \\
\hline 217 & -.0050 & -0.91 & 20 \\
\hline 236 & -.0050 & -0.46 & 20 \\
\hline 1212 & -.0037 & -0.24 & 14 \\
\hline 168 & -.0022 & -0.22 & 15 \\
\hline 260 & -.0017 & -0.14 & 20 \\
\hline 218 & -.0014 & -0.14 & 16 \\
\hline 207 & .0001 & 0.00 & 17 \\
\hline 203 & .0002 & 0.01 & 19 \\
\hline 257 & .0006 & 0.07 & 20 \\
\hline 141 & .0006 & 0.02 & 20 \\
\hline 245 & .0009 & 0.08 & 20 \\
\hline 232 & .0011 & 0.12 & 15 \\
\hline 172 & .0011 & 0.05 & 14 \\
\hline 221 & .0017 & 0.07 & 20 \\
\hline 176 & .0019 & 0.08 & 17 \\
\hline 201 & .0024 & 0.26 & 20 \\
\hline 142 & .0030 & 0.18 & 20 \\
\hline 256 & .0037 & 0.31 & 12 \\
\hline 1000 & .0040 & 0.30 & 12 \\
\hline 208 & .0044 & 0.40 & 14 \\
\hline 1268 & .0048 & 0.58 & 19 \\
\hline 175 & .0048 & 0.57 & 20 \\
\hline 192 & .0054 & 0.46 & 14 \\
\hline 178 & .0055 & 0.46 & 20 \\
\hline 144 & .0056 & 0.65 & 14 \\
\hline 177 & .0060 & 0.69 & 20 \\
\hline 157 & .0060 & 0.20 & 20 \\
\hline 152 & .0065 & 0.59 & 20 \\
\hline 215 & .0074 & 0.50 & 20 \\
\hline
\end{tabular}


TABLE 3 (Continued)

\begin{tabular}{|c|c|c|c|}
\hline $\begin{array}{l}\text { Fund ID } \\
\text { Number }\end{array}$ & $\dot{\square}$ & $t(\hat{\square})=\frac{\square}{\square(\hat{\square})}$ & $\begin{array}{c}\text { Number of } \\
\text { Observations }\end{array}$ \\
\hline 151 & .0108 & 0.82 & 20 \\
\hline 226 & .0108 & 0.85 & 20 \\
\hline 246 & .0112 & 1.06 & 15 \\
\hline 2268 & .0125 & 1.88 & 17 \\
\hline 225 & .0139 & 1.31 & 20 \\
\hline 2262 & .0140 & 1.43 & 15 \\
\hline 250 & .0145 & 1.02 & 15 \\
\hline 2186 & .0164 & 0.65 & 14 \\
\hline 206 & .0165 & 1.09 & 11 \\
\hline 227 & .0170 & 1.40 & 14 \\
\hline 169 & .0191 & 1.89 & 20 \\
\hline 267 & .0198 & 0.99 & 10 \\
\hline 234 & .0219 & 1.21 & 14 \\
\hline 162 & .0219 & 0.86 & 20 \\
\hline 233 & .0232 & 1.34 & 20 \\
\hline 1186 & .0582 & 2.03 & 14 \\
\hline
\end{tabular}

TABLE 4

Frequency Distribution Of Estimated Intercepts For Equation (8)

For 115 Mutual Funds For Several Time Intervals. Fund Returns Calculated Both Net And Gross Of Expenses

\begin{tabular}{|c|c|c|c|c|}
\hline \multirow[b]{2}{*}{ Class Interval } & \multicolumn{2}{|c|}{$\begin{array}{l}\text { All Funds Entire } \\
\text { Sample Period* }\end{array}$} & \multirow{2}{*}{$\begin{array}{c}56 \text { Funds } \\
20 \text { Years } \\
1945-64 \\
\text { Gross } \\
\text { Returns }\end{array}$} & \multirow{2}{*}{$\begin{array}{c}\text { All Funds } \\
10 \text { Years } \\
1955-64 \\
\text { Gross } \\
\text { Returns }\end{array}$} \\
\hline & $\begin{array}{c}\text { Net } \\
\text { Gross }\end{array}$ & $\begin{array}{c}\text { Gross } \\
\text { Returns }\end{array}$ & & \\
\hline & (1) & (2) & (3) & (4) \\
\hline $.06 \square \hat{D}<.07$ & 0 & 1 & 0 & 0 \\
\hline $.05 \square \hat{D}<.06$ & 1 & 0 & 0 & 1 \\
\hline $.04 \square \hat{\square}<.05$ & 0 & 0 & 0 & 0 \\
\hline $.03 \square \hat{D}<.04$ & 0 & 1 & 1 & 1 \\
\hline $.02 \square \hat{D}<.03$ & 3 & 9 & 2 & 12 \\
\hline $.01 \square \hat{D}<.02$ & 12 & 16 & 8 & 15 \\
\hline $.0 \square \hat{D}<.01$ & 23 & 21 & 13 & 31 \\
\hline$\square .01<\hat{\square}<.0$ & 22 & 29 & 17 & 12 \\
\hline$\square .02<\hat{\square} \square \square .01$ & 21 & 14 & 6 & 13 \\
\hline 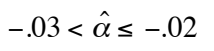 & 12 & 11 & 5 & 12 \\
\hline 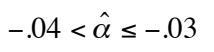 & 9 & 9 & 2 & 3 \\
\hline$\square .05<\hat{\square} \square \square .04$ & 8 & 1 & 1 & 1 \\
\hline$\square .06<\hat{\square} \square \square .05$ & 1 & 1 & 1 & 1 \\
\hline$\square .07<\hat{\square}$ ८०.06 & 1 & 0 & 0 & 0 \\
\hline 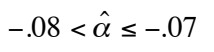 & 1 & 2 & 0 & 0 \\
\hline$\square .09<\hat{0} \square 0.08$ & 1 & 0 & 0 & 1 \\
\hline Average $\dot{\square}$ & -.011 & -.004 & -.032 & -.001 \\
\hline
\end{tabular}

* Sample sizes range from 10 to 20 annual observations among the funds. 
The average value of $\dot{\square}$ calculated net of expenses was -.011 which indicates that on average the funds earned about $1.1 \%$ less per year (compounded continuously) than they should have earned given their level of systematic risk. It is also clear from Figure 1 that the distribution is skewed to the low side with 76 funds having $\hat{\square}<0$ and only 39 with $\vec{\square}>0$.

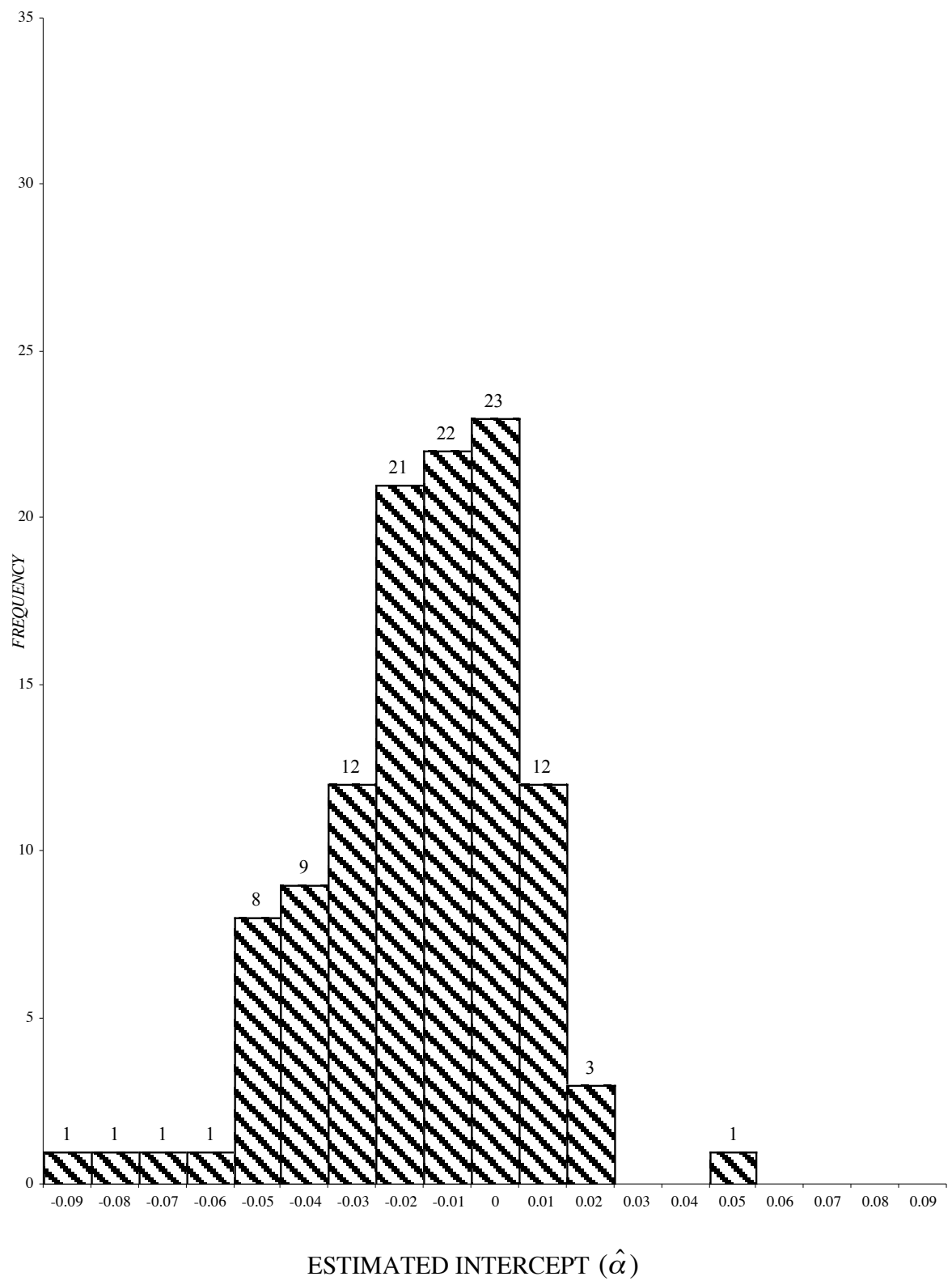

Figure 1

Frequency distribution (from col. (1), Table 4) of estimated intercepts $(\hat{\square})$ for eq. (8) for 115 mutual funds for all years available for each fund. Fund returns calculated net of all expenses. 
The model implies that with a random selection buy and hold policy one should expect on average to do no worse than $\square=0$. Thus it appears from the preponderance of negative $\vec{\square}$ 's that the funds are not able to forecast future security prices well enough to recover their research expenses, management fees and commission expenses.

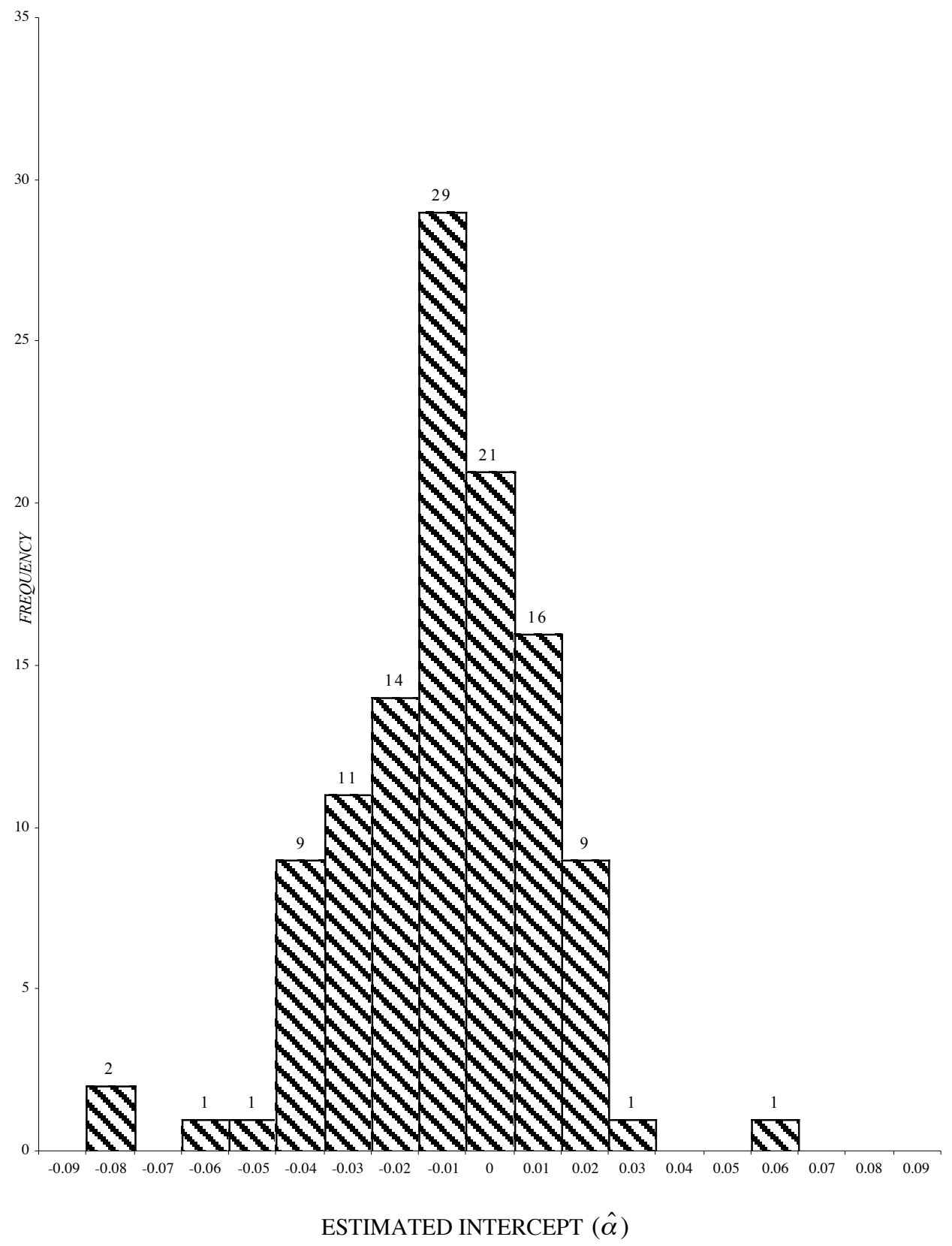

Figure 2

Frequency distribution (from col. (2), Table 4) of estimated intercepts $(\hat{\square})$ for eq. (8) for 115 mutual funds for all years available for each fund. Fund returns calculated gross of all management expenses. 


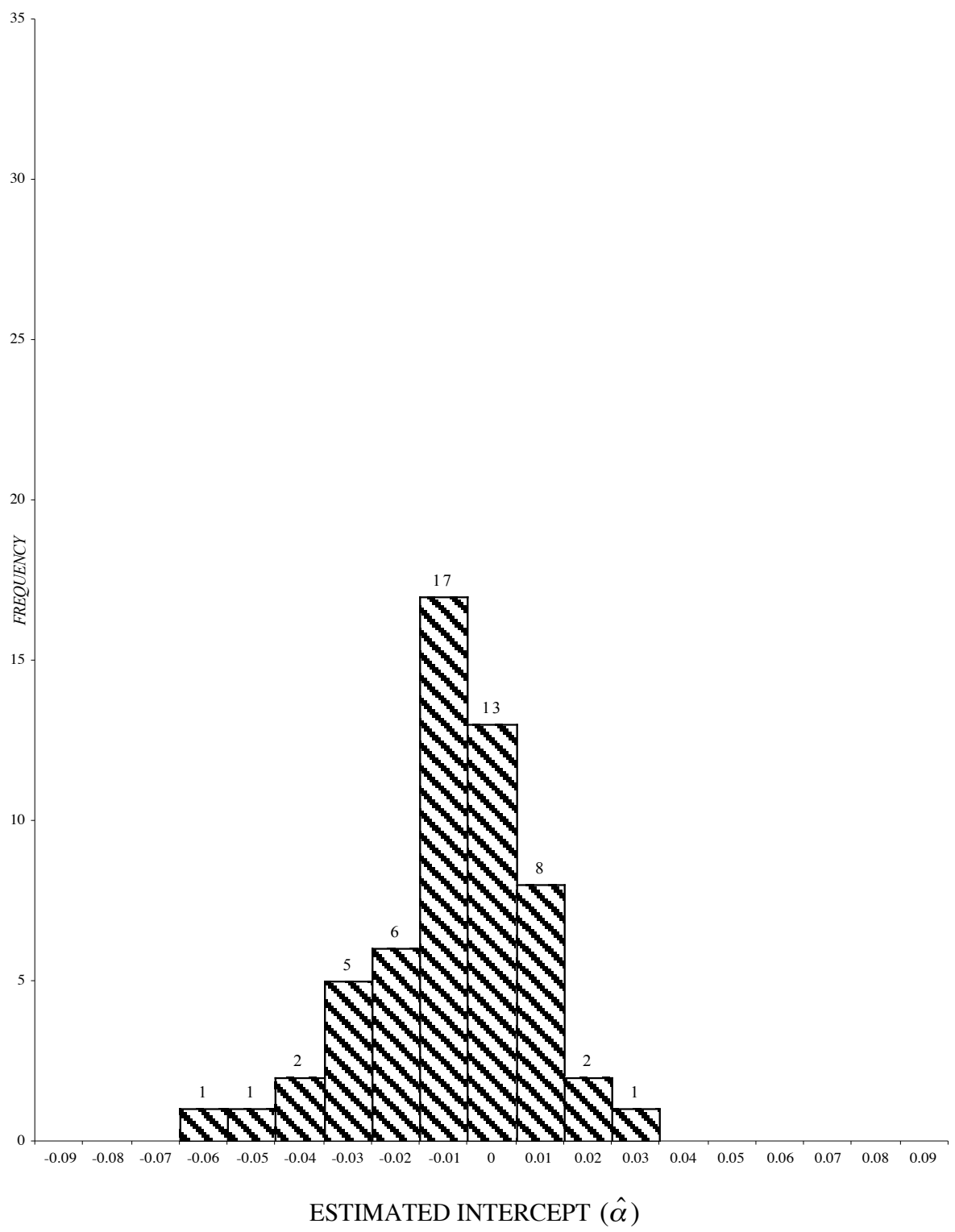

Figure 3

Frequency distribution (from col. (3), Table 4) of estimated intercepts $(\hat{\square})$ for eq. (8) for 56 mutual funds for which complete data were available in the period 1945-64. Fund returns calculated gross of all management expenses.

In order to examine this point somewhat more closely the $\hat{\square}$ 's were also estimated on the basis of returns calculated gross of all management expenses. ${ }^{22}$ That is $\tilde{R}_{j t}$ was taken to be

$$
\tilde{R}_{j t}=\log _{e} \frac{\square \tilde{N} A_{j t}+C \tilde{G}_{j t}+I \tilde{D}_{j t}+\tilde{E}_{j t}}{N A_{j, t \square 1}}
$$

22 It would be desirable to use the fund returns gross of all expenses including brokerage commissions as well as the management expenses. However, overall commission data are not yet available. 


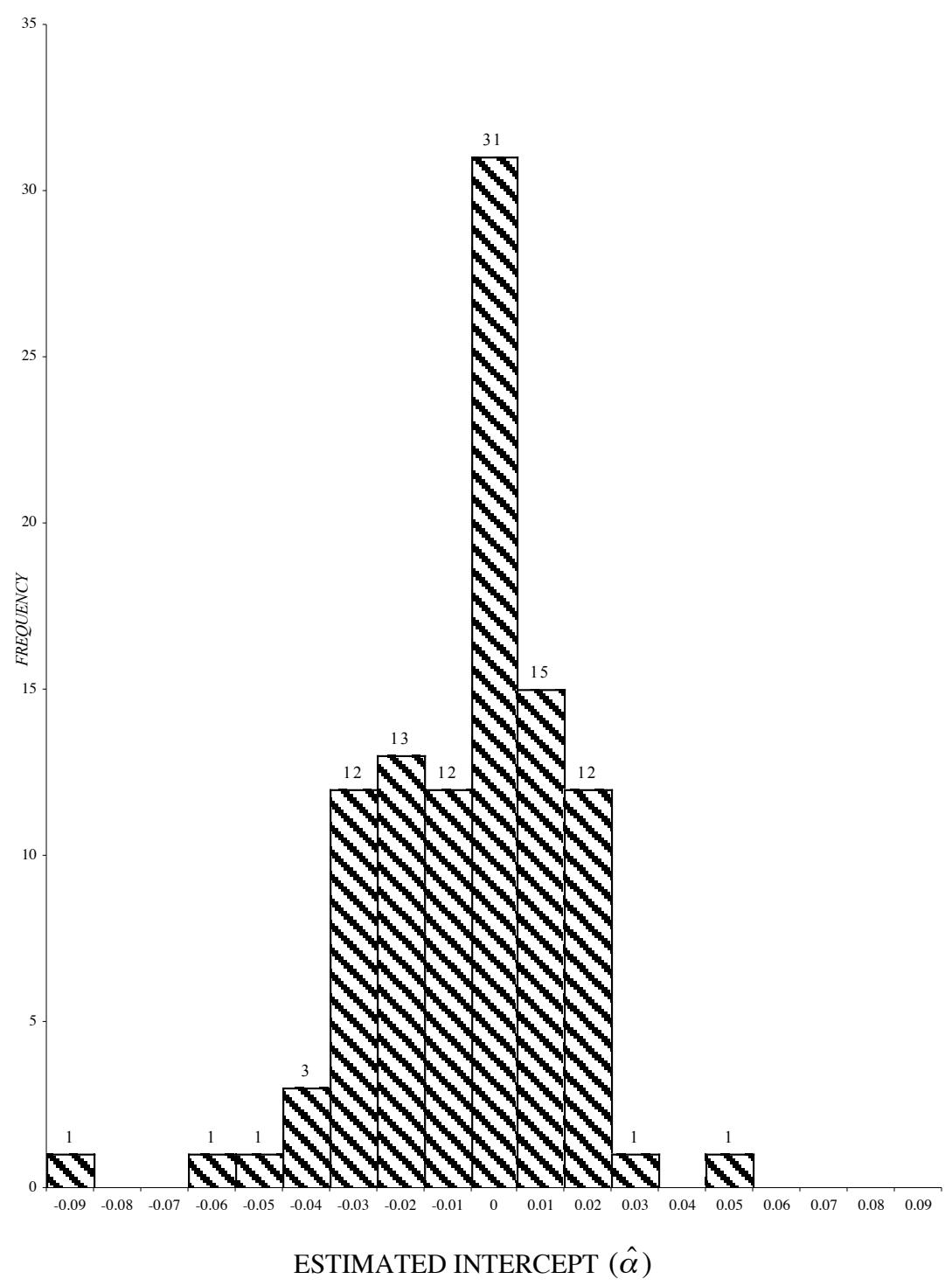

Figure 4

Frequency distribution (from col. (4), Table 4) of estimated intercepts $(\hat{\square})$ for eq. (8) for 115 mutual funds for the 10 years 1955-64. Fund returns calculated gross of al1 management expenses.

where $E_{j t}$, is the estimated per share dollar value of all expenses except brokerage commissions, interest and taxes (the latter two of which are small) for the $j$ 'th fund in year $t$ obtained from (1955 and 1965). Now when the estimates are based on gross returns any forecasting success of the funds (even if not sufficient to cover their expenses) should be revealed by positive $\hat{Q}^{\prime}$ 's. 
The results shown in Column 2 of Table 4 indicate the average $\vec{\square}$ estimated from gross return data was -.004 or $-.4 \%$ per year, with 67 funds for which $\hat{\square}<0$ and 48 for which $\vec{\square}>0$. The frequency distribution, plotted in Figure 2, is much more symmetric than the distribution obtained from the net returns. Thus it appears that on average during this 20 -year period the funds were not able to increase returns enough by their trading activities to recoup even their brokerage commissions (the only expenses which were not added back to the fund returns).

In order to avoid the difficulties associated with non-identical time periods and unequal sample sizes, the measures for the 56 funds for which data were available for the entire 20-year period are summarized in Column 3 of Table 4 and Figure 3. The results indicate an average $\square$ of -.032 with 32 funds for which $\square_{j}<0$ and 24 funds for which $\square j>0$. It is very likely that part of this apparently poorer gross performance is due to the method used in approximating the expenses for the years prior to 1955. It was noted earlier that the expenses for these earlier years were assumed to be equal to the expenses for 1955. But since these expense ratios were declining in the earlier period these estimates are undoubtedly too low.

Finally in order to avoid any difficulty associated with the estimates of the expenses before 1955, the measures were estimated for each of the 115 funds using only the gross return data in the 10-year period 1955-64. The frequency distribution of the $\square^{\prime}$ 's is given in Column 4 of Table 4 and Figure 4 . The average $\vec{\square}$ for this period was -.001 or $-.1 \%$ per year with 55 funds for which $\hat{\square}<0$ and 60 funds for which $\vec{\square}>0$. The reader must be careful about placing too much significance on the seemingly larger number of funds with $\dot{\square}>0$. It is well known that measurement errors (even though unbiased) in any independent variable will cause the estimated regression coefficient of that variable to be attenuated towards zero (cf. Johnson (1963, chap. 6)). Since we know that there are undoubtedly some errors in the measurement of both the riskless rate and the estimated returns on the market portfolio, the coefficients $\hat{D}_{j}$ are undoubtedly slightly downward 
biased. This of course results in an upward bias in the estimates of the $\hat{Q}_{j}$ since the least squares regression line must pass through the point of means.

There is one additional item which tends to bias the results slightly against the funds. That is, the model implicitly assumes the portfolio is fully invested. But since the mutual funds face stochastic inflows and outflows they must maintain a cash balance to meet them. Data presented in Friend (1962, pp. 120-127) indicate that on average the funds appear to hold about $2 \%$ of their total net assets in cash. If we assume the funds had earned the riskless rate on these assets (about $3 \%$ per year) this would increase their returns (and the average $\hat{\square}$ ) by about $(.02)(.03)=.0006$ per year. Thus the adjusted average $\hat{\square}$ is about -.0004 , and it is now getting very difficult to say that this is really different from zero. Thus, let us now give explicit consideration to these questions of "significance."

The "Significance" of the Estimates.-We now address ourselves to the question regarding the statistical significance of the estimated performance measures. Table 3 presents a listing of the " $t$ " values for the individual funds, the intercepts, and the number of observations used in obtaining each estimate. We noted earlier that it is possible for a fund manager to do worse than a random selection policy since it is easy to lower a fund's returns by un-wisely spending resources in unsuccessful attempts to forecast security prices. The fact that the $\square$ 's shown in Table 3 and Figure 1 are skewed to the left indicate this may well be true. Likewise an examination of the " $t$ " values given in Table 3 and plotted in Figure 5 indicates that the $t$ values for 14 of the funds were less than -2 and hence are all significantly negative at the 5\% leve1.23 However, since we had little doubt that it was easy to do worse than a random policy we are really interested mainly in testing the significance of the large positive performance measures.

\footnotetext{
23 The $t$ value for $5 \%$ level of significance (one-tail) with 8 degrees of freedom (the minimum in the sample) is 1.86 and for 18 degrees of freedom (the maximum in the sample) is 1.73 .
} 


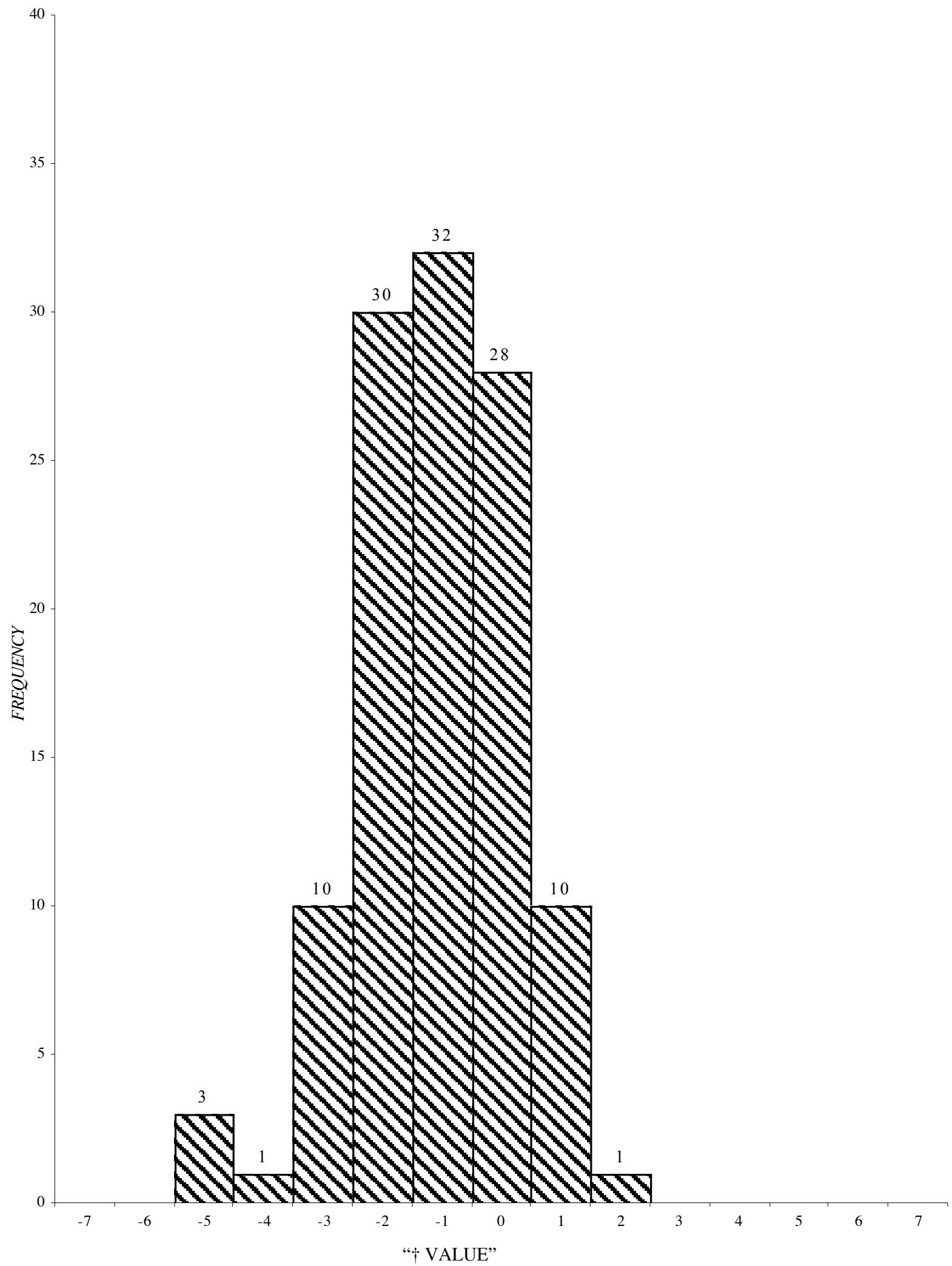

Figure 5

Frequency distribution (from col, (1), Table 5) of "t" values for estimated intercepts in eq. (8) for 115 mutual funds for all years available for each fund. Fund returns calculated net of all expenses. 


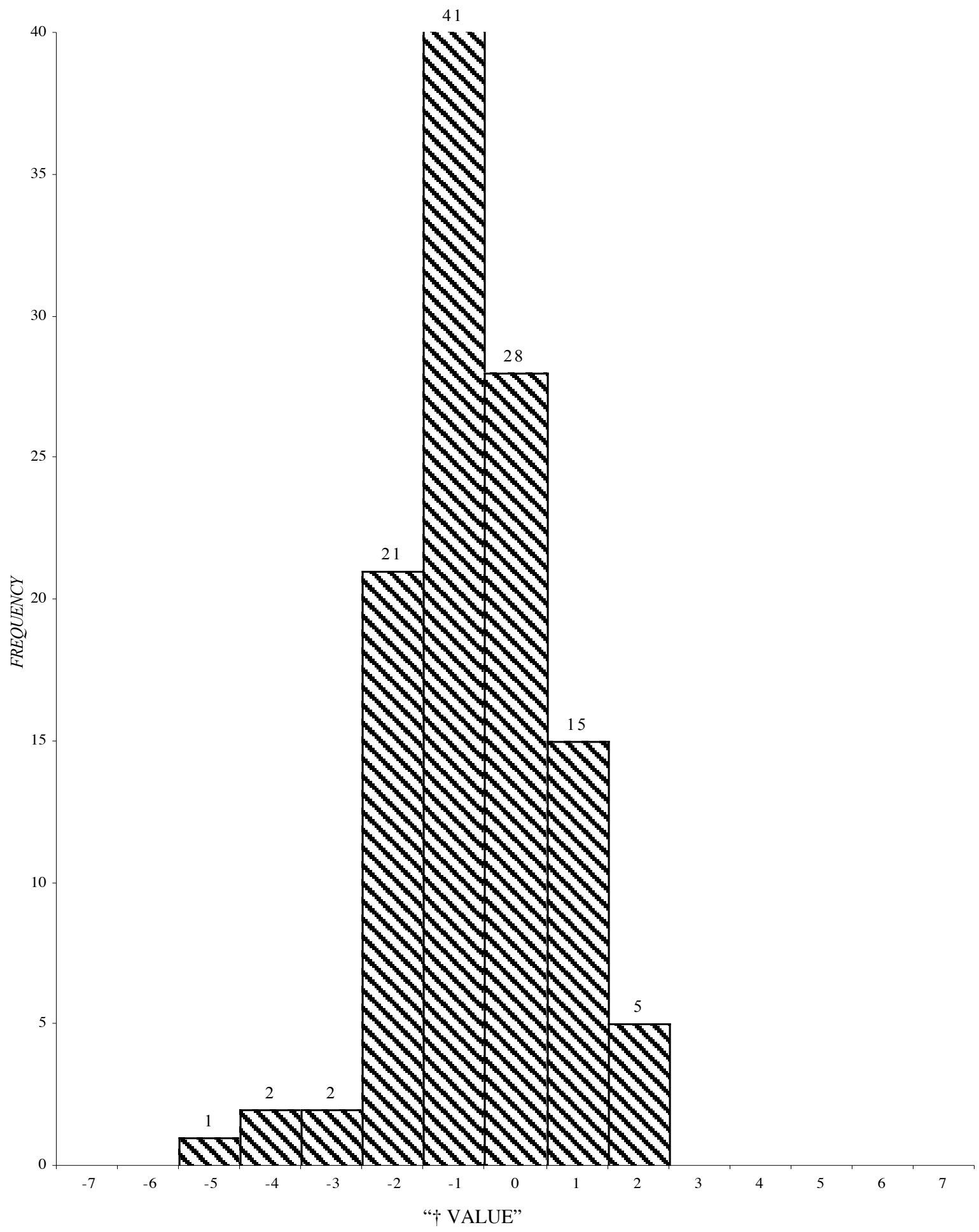

Figure 6

Frequency distribution (from col. (2), Table 5) of " $t$ " values for estimated intercepts in eq. (8) for 115 mutual funds for all years available for each fund. Fund returns calculated gross of all expenses. 


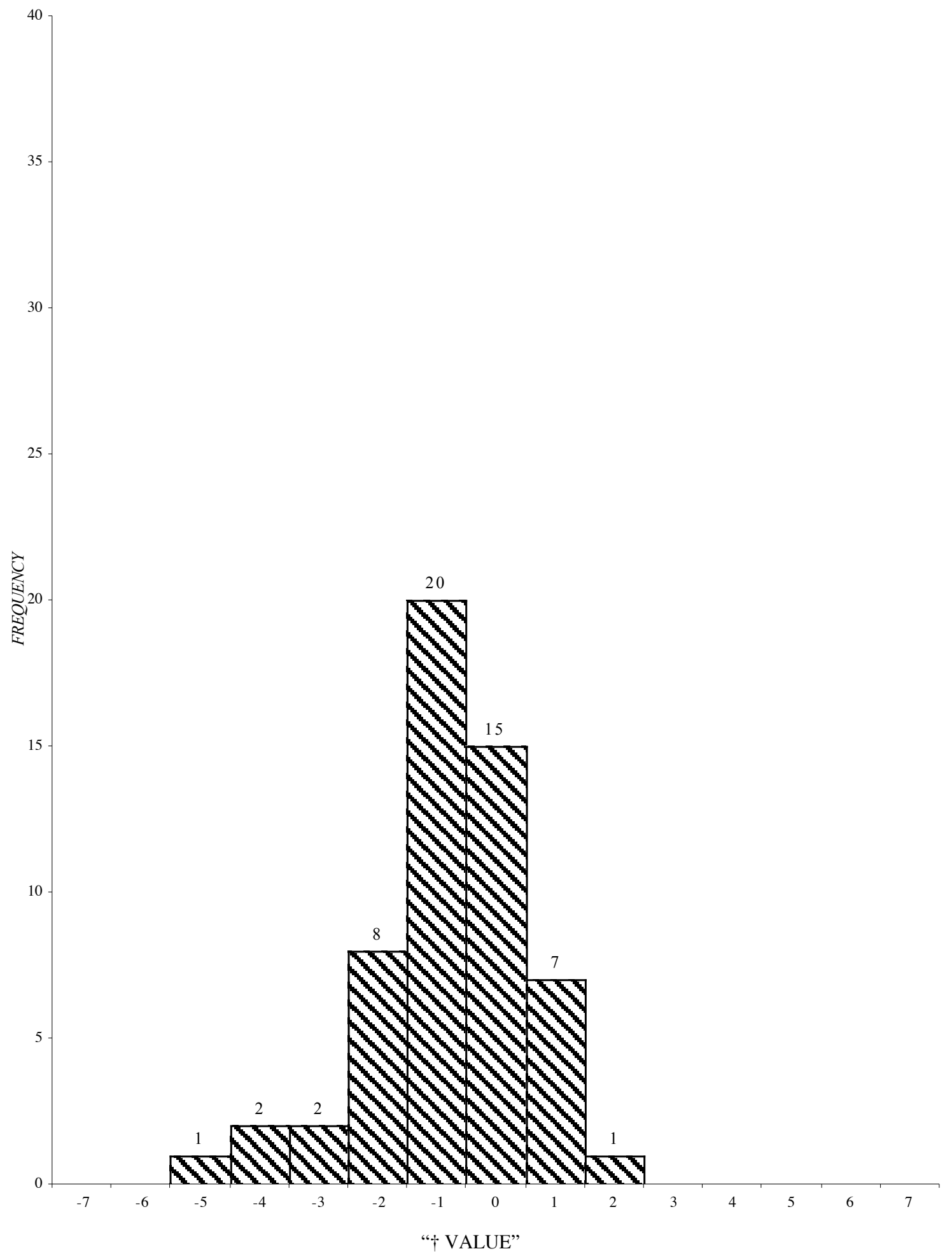

\section{Figure 7}

Frequency distribution (from col. (3), Table 5) of " $t$ " values for estimated intercepts in eq. (8) for 56 mutual funds for which complete data were available in the period 1945-64. Fund returns calculated gross of all management expenses. 


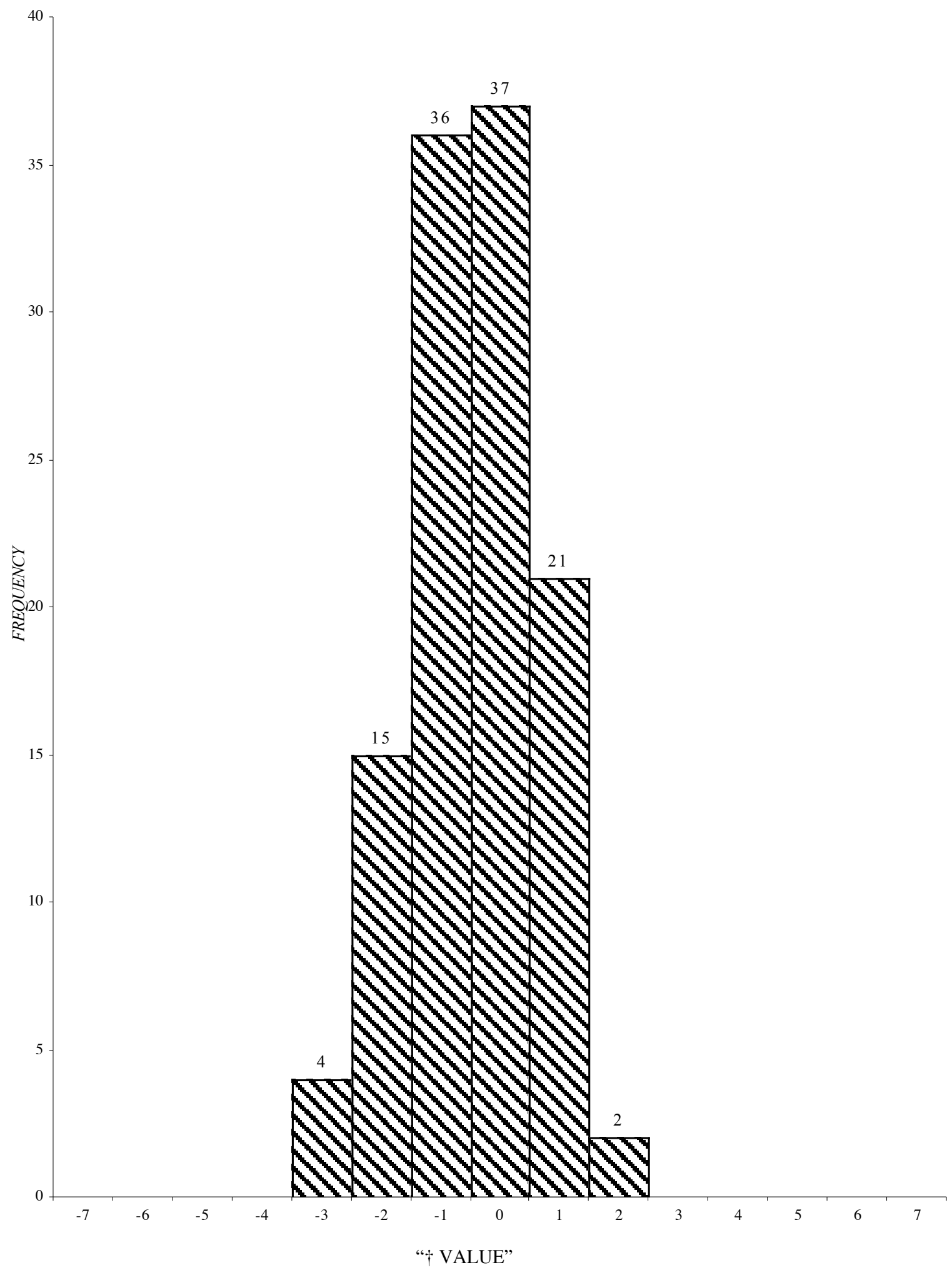

Figure 8

Frequency distribution (from col. (4), Table 5) of "t" values for estimated intercepts in eq. (8) for 115 mutual funds for the 10 year period 1955-64. Fund returns calculated gross of all management expenses. 
An examination of Column 3 of Table 3 reveals only 3 funds which have performance measures which are significantly positive at the $5 \%$ level. But before concluding that these funds are superior we should remember that even if all 115 of these funds had a true $\sqcup$ equal to zero, we would expect (merely because of random chance) to find $5 \%$ of them or about 5 or 6 funds yielding $t$ values "significant" at the $5 \%$ level. Thus, henceforth we shall concentrate on an examination of the entire frequency distribution of the estimated $t$ values to see whether we observe more than the expected number of significant values. Unfortunately because of the differing degrees of freedom among the observations plotted in Figure 5 and Figure 6 (which contains the gross estimates), the frequency distributions are somewhat difficult to interpret.

However Figure 7 presents the frequency distribution of the $t$ values calculated on the basis of gross returns for the 56 funds for which 20 complete years of data were available. The $t$ value for the one-tail $2.5 \%$ level of significance is 2.1 , and thus we expect $(.025)(56)=1.4$ observations with $t$ values greater than 2.1. We observe just one. Again we also observe a definite skewness towards the negative values and no evidence of an ability to forecast security prices. It is interesting to note that if the model is valid and if we have indeed returned all expenses to the funds, these distributions should be symmetric about zero. However, we have not added back any of the brokerage commissions and have used estimates of the expenses for the years 1945-54 which we strongly suspect are biased low. Thus the results shown in Figure 7 are not too surprising.

As mentioned above, in order to avoid some of these difficulties and to test more precisely whether or not the funds were on average able to forecast well enough to cover their brokerage expenses (even if not their other expenses) the performance measures were estimated just for the period 1955-64, The frequency distribution for the $t$ values of the intercepts of the 115 funds estimated from gross returns is given in Figure 8 and column 4 of Table 5. All the observations have 8 degrees of freedom, and the maximum and minimum values are respectively +2.17 and -2.84 . It seems clear from the symmetry 
of this distribution about zero and especially from the lack of any values greater than +2.2 that there is very little evidence that any of these 115 mutual funds in this 10 -year period possessed substantial forecasting ability. We refrain from making a strict formal interpretation of the statistical significance of these numbers and warn the reader to do likewise since there is a substantial amount of evidence (cf. Fama (1965), Roll (1968)) which indicates the normality assumptions on the residuals, $\tilde{u}_{j t}$, of (8) may not be valid. We also point out that one could also perform chi-square goodness of fit tests on the $t$ distributions presented, but for the same reasons mentioned above we refrain from doing so. That is, if the residuals are not normally distributed the estimates of the parameters will not be distributed according to the student $t$ distribution, and therefore it doesn't really make sense to make formal goodness of fit tests against the " $t$ " distribution.

\section{TABLE 5}

Frequency Distribution Of “ $t$ " Values* For Estimated Intercepts In Equation (8) For 115 Mutual Funds For Several Time Intervals. Fund Returns Calculated Both Net And Gross Of Expenses

\begin{tabular}{|c|c|c|c|c|}
\hline \multirow[b]{2}{*}{ Class Interval } & \multicolumn{2}{|c|}{$\begin{array}{l}\text { All Funds Entire } \\
\text { Sample Period** }\end{array}$} & \multirow{2}{*}{$\begin{array}{c}56 \text { Funds } \\
20 \text { Years } \\
1945-64 \\
\text { Gross } \\
\text { Returns }\end{array}$} & \multirow{2}{*}{$\begin{array}{c}\text { All Funds } \\
10 \text { Years } \\
1955-64 \\
\text { Gross } \\
\text { Returns }\end{array}$} \\
\hline & $\begin{array}{c}\text { Net } \\
\text { Gross }\end{array}$ & $\begin{array}{l}\text { Gross } \\
\text { Returns }\end{array}$ & & \\
\hline & (1) & (2) & (3) & (4) \\
\hline $4 \square t(\hat{\square})<5$ & 0 & 0 & 0 & 0 \\
\hline $3 \square t(\hat{\square})<4$ & 0 & 0 & 0 & 0 \\
\hline $2 \square t(\hat{\square})<3$ & 1 & 5 & 1 & 2 \\
\hline $1 \square t(\hat{\square})<2$ & 10 & 15 & 7 & 21 \\
\hline $0 \square t(\hat{\square})<1$ & 28 & 28 & 15 & 37 \\
\hline$\square 1<t(\grave{\square}<<0$ & 32 & 41 & 20 & 36 \\
\hline$\square 2<t(\grave{\square}) \square \square 1$ & 30 & 21 & 8 & 15 \\
\hline$\square 3<t(\hat{\square}) \square \square 2$ & 10 & 2 & 2 & 4 \\
\hline$\square 4<t(\hat{\square}) \square \square 3$ & 1 & 2 & 2 & 0 \\
\hline$\square 5<t(\hat{\square}) \square \square 4$ & 3 & 1 & 1 & 0 \\
\hline
\end{tabular}

* Defined as $t\left(\square_{j}\right)=\frac{\square_{j}}{\square\left(\square_{j}\right)}$

** Sample sizes from 10 to 20 annual observations among the funds. 
However, while the possible non-normality of these disturbances causes problems in attempting to perform the usual types of significance tests, it should be emphasized that the model itself is in no way crucially dependent on this assumption. Wise (1963) has shown that the least squares estimates of $b_{j}$ in (2) are unbiased and consistent if the disturbance terms $u_{j}$ conform to the symmetric and finite mean members of the stable class of distributions. Furthermore, Fama (1967) has demonstrated that the capital asset pricing model results (eq. (1)) can still be obtained in the context of these distributions. A complete discussion of the issues associated with this distributional problem and their relationship to the portfolio evaluation problem is available in Jensen (1967) and will not be repeated here. It is sufficient to reiterate the fact that the normality assumption is necessary only in order to perform the strict tests of significance, and we warn the reader to interpret these tests as merely suggestive until the state of stable distribution theory is developed to the point where strict tests of significance can be legitimately performed.

It is important to note in examining the empirical results presented above that the mutual fund industry (as represented by these 115 funds) shows very little evidence of an ability to forecast security prices. Furthermore there is surprisingly little evidence that indicates any individual funds in the sample might be able to forecast prices. These results are even stronger when one realizes that the biases in the estimates ${ }^{24}$ all tend to either exaggerate the magnitude of any forecasting ability which might exist ${ }^{25}$ or tend to show evidence of forecasting ability where none exists.

\section{Conclusion}

The evidence on mutual fund performance discussed above indicates not only that these 115 mutual funds were on average not able to predict security prices well enough to

\footnotetext{
24 Except for the assumption of a fully invested portfolio which we have allowed for by assuming cash earned interest at the riskless rate.

25 See Section II.
} 
outperform a buy-the-market-and-hold policy, but also that there is very little evidence that any individual fund was able to do significantly better than that which we expected from mere random chance. It is also important to note that these conclusions hold even when we measure the fund returns gross of management expenses (that is assume their bookkeeping, research, and other expenses except brokerage commissions were obtained free). Thus on average the funds apparently were not quite successful enough in their trading activities to recoup even their brokerage expenses.

It is also important to remember that we have not considered in this paper the question of diversification. Evidence reported elsewhere (cf. Jensen (1967)) indicates the funds on average have done an excellent job of minimizing the "insurable" risk born by their shareholders. Thus the results reported here should not be construed as indicating the mutual funds are not providing a socially desirable service to investors; that question has not been addressed here. The evidence does indicate, however, a pressing need on the part of the funds themselves to evaluate much more closely both the costs and the benefits of their research and trading activities in order to provide investors with maximum possible returns for the level of risk undertaken.

\section{References}

Blume, Marshall. 1968. "The Assessment of Portfolio Performance". Chicago, IL: University of Chicago. Unpublished $\mathrm{Ph}$. D. dissertation.

Cohen, Kalman J. and Jerry A. Pogue. 1967. "An Empirical Evaluation of Alternative Portfolio Selection Models." Journal of Business 40: pp 166-193.

Dietz, Peter. 1966. Pension Funds: Measuring Investment Performance. New York: The Free Press.

Fama, Eugene F. 1965. "The Behavior of Stock Market Prices." Journal of Business 37: January 1965, pp 34-105.

Fama, Eugene F. 1967. "Risk, Return, and General Equilibrium in a Stable Paretian Market". Chicago, IL: University of Chicago. Unpublished manuscript. 
Fama, Eugene F. 1968. "Risk, Return, and Equilibrium: Some Clarifying Comments." Journal of Finance 23: pp 29-40.

Farrar, Donald E. 1962. The Investment Decision Under Uncertainty. Englewood Cliffs, NJ: Prentice Hall, Inc.

Friend, Irwin, F. E. Brown, Edward S. Herman, and Douglas Vickers. 1962. A Study of Mutual Funds. Washington, D.C.: U.S. Government Printing Office.

Friend, Irwin and Douglas Vickers. 1965. "Portfolio Selection and Investment Performance." Journal of Finance 20: pp 391-415.

Horowitz, Ira. 1965. "A Model for Mutual Fund Evaluation." Industrial Management Review 6: pp 81-92.

Jensen, Michael C. 1967. "Risk, the Pricing of Capital Assets, and Evaluation of Investment Portfolios". Chicago, IL: University of Chicago. Unpublished preliminary draft of $\mathrm{Ph}$. D. thesis.

Johnston, J. 1963. Econometric Methods. New York: McGraw Hill, Inc.

King, Benjamin F. 1966. "Market and Industry Factors in Stock Price Behavior." Journal of Business 39, Part 2: pp 139-190.

Lintner, John. 1965a. "Security Prices, Risk, and Maximal Gains from Diversification." Journal of Finance 20: December, pp 587-616.

Lintner, John. 1965b. "The Valuation of Risk Assets and the Selection of Risky Investments in Stock Portfolios and Capital Budgets." Review of Economics and Statistics 47: pp 13-37.

Mandelbrot, Benoit. 1963. "The Variation of Certain Speculative Prices." Journal of Business 36: October, pp 394-419.

Markowitz, Harry. 1959. Portfolio Selection: Efficient Diversification of Investments. New York: Wiley.

Roll, Richard. 1968. The Efficient Market Model Applied to U.S. Treasury Bill Rates. Unpublished Ph. D. dissertation, University of Chicago.

Sharpe, William F. 1963. "A Simplified Model for Portfolio Analysis." Management Science 19: September, pp 425-442.

Sharpe, William F. 1964. "Capital Asset Prices: A Theory of Market Equilibrium under Conditions of Risk." Journal of Finance 19: September, pp 425-442.

Sharpe, William F. 1966. "Mutual Fund Performance." Journal of Business 39, Part 2: pp 119-138. 
Sharpe, William F. 1967. "Linear Programming Algorithm for Mutual Fund Portfolio Selection." Management Science 13: pp 499-510.

Standard \& Poor. 1964. "Trade and Securities Statistics: Security Price Index Record". Orange, CT: Standard and Poor's Corporation.

Treynor, Jack L. 1965. "How to Rate Management of Investment Funds." Harvard Business Review XLIII: pp 63-75.

Treynor, Jack L. Undated. "Toward a Theory of Market Value of Risky Assets". Unpublished manuscript, undated.

Wiesenberger, Arthur. 1955 and 1965. Investment Companies. New York: Arthur Wiesenberger \& Company.

Wise, John. 1963. "Linear Estimators for Linear Regression Systems Having Infinite Variances". Unpublished paper presented at the Berkeley-Stanford Mathematical Economics Seminar. 